\title{
Wayang Sebagai Media Komunikasi Simbolik Perilaku Manusia Dalam Praktek Budaya Dan Agama Di Bali
}

\author{
I Gusti Ngurah Seramasara \\ Institut Seni Indonesia Denpasar \\ aseramasara@gmail.com
}

\begin{abstract}
Wayang sebagai seni pertunjukan merupakan media komunikasi simbolik perilaku manusia dalam praktek agama dan budaya sudah dikenal sejak jaman pra Hindu. Ritual bayang-bayang dalam kepercayaan animisme dan dinamisme merupakan praktek budaya dan agama untuk memuja roh nenek moyang. Tulisan ini bertujuan untuk mengetahui implementasi pertunjukan wayang sebagai media komunikasi simbolik dalam praktek budaya dan agama di Bali. Permasalahan yang diangkat melalui penulisan ini adalah ingin menginvestigasi apakah pertunjukan wayang dalam praktik budaya dan agama di Bali, dipahami dan dihadirkan sebagai ujud pemujaan pada kekuatan gaib sebagai perkembangan dari tradisi pra Hindu. Metode yang digunakan untuk mengkaji masalah di atas adalah metode penelitian kualitatif dengan teori interaksi simbolik dan komunikasi. Penulisan ini ingin menunjukan bahwa wayang sebagai media komunikasi simbolik perilaku manusia dalam praktek budaya dan agama di Bali telah dilakukan sejak jaman pra Hindu dan masih dipertahankan oleh orang Bali sampai sekarang. Kekuatan gaib yang dapat mengganggu manusia masih dipercaya oleh masyarakat Bali, terutama pada anak yang lahir pada tumpek wayang, sehingga perlu diruwat (dibersihkan) gangguan itu dengan wayang sapuh leger.
\end{abstract}

Kata kunci: wayang, komunikasi simbolik, praktek budaya dan agama

\section{Wayang As A Symbolic Communication Media Of Human Behavior In Culture And Religion Practices In Bali}

Puppet as a performing art is a symbolic communication media of human behavior in the practice of religion and culture that has been known since pre-Hindu times. The shadow rituals in animist beliefs and dynamism are cultural and religious practices to worship ancestral spirits. This paper aims to determine the implementation of puppet shows as a symbolic communication medium in cultural and religious practices in Bali. The problem raised through this paper is to investigate whether puppet performances in cultural and religious practices in Bali are understood and presented as a form of worship of magical powers as a development of pre-Hindu traditions. The method used to examine the problem above is a qualitative research method with the theory of symbolic and communication interaction. This writing wants to show that puppets as symbolic communication media of human behavior in cultural and religious practices in Bali have been carried out since pre-Hindu times and are still maintained by Balinese until now. The supernatural powers that can disturb humans are still trusted by Balinese people, especially in children born at puppet shows, so it needs to be tampered with (cleaned) the interference with sapuh leger puppets.

Keywords: puppets, symbolic communication, cultural and religious practices

Proses Review : 7 - 25 Januari 2019, Dinyatakan Lolos: 29 Januari 2019 


\section{PENDAHULUAN}

Wayang sebagai sebuah seni pertunjukan merupakan komunikasi simbolik prilaku manusia dalam praktek agama dan budaya. Wayang sebagai komunikasi simbolik dalam kehidupan agama dan budaya sudah dikenal sejak jaman pra Hindu. Ritual bayangbayang dalam kepercayaan animisme dan dinamisme mempunyai fungsi sebagai pemujaan pada "hyang". Pemujaan pada "hyang" merupakan pemujaan terhadap roh nenek moyang, yang di yakini dapat mengganggu kehidupan manusia. Pemujaan terhadap roh nenek moyang merupakan praktek budaya dan agama dalam masyarakat Indonesia sejak jaman pra Hindu.

Ritual bayang-bayang sebagai praktek budaya dan agama pada jaman pra Hindu di Indonesia dipimpin oleh seorang Syaman atau Kepala Suku, sehingga Syaman dapat disejajarkan dengan Mangku Dalang saat ini. Seorang kepala suku dalam masyarakat pra Hindu diyakini memiliki kemampuan untuk menghubungkan roh nenek moyang dengan keluraga atau masyarakat (Mulyono, 1978:43). Berdasarkan keyakinan itu seorang kepala suku sangat ditaati dan segala perintahnya selalu diikuti oleh sukunya. Oleh karena itu seorang kepala suku tidak hanya ditempatkan sebagai pemimpin dalam dunia nyata tetapi juga dianggap sebagai pemimpin spiritual, sehingga disebut dengan "syaman" (orang sakti yang memiliki kemampuan untuk menghubungkan manusia dengan kekuatan gaib). Dalam masyarakat Bali, seorang mangku dalang juga dianggap mempunyai kekuatan spiritual yang tinggi karena seorang mangku dalang dalam pertunjukan wayang berperan mengkomunikasikan antara manusia dengan dewa.

Wayang tidak hanya dihadirkan sebagai seni pertunjukan untuk dinikmati sebagai sajian estetik, tetapi mengandung makna simbolik yang dikomunikasikan sebagai pedoman moral bagi manusia. Berbagai karakter yang ditampilkan dalam pertunjukan wayang untuk memberikan bayangan kepada masyarakat sebagai pedoman prilaku. Oleh karena itu tulisan ini bertujuan untuk mengetahui implementasi pertunjukan wayang sebagai media komunikasi simbolik prilaku manusia dalam bidang budaya dan agama di Bali. Sangat dapat dipahami bahwa pertunjukan wayang di Bali merupakan media komunikasi nilai budaya yang dapat dijadikan pedoman prilaku. Dalam kaitannya dengan agama pertunnjukan wayang tetap dijadikan sarana upacara bahkan bagian dari upacara terutama wayang sapuhleger atau wayang pengruwatan.

Pertunjukan wayang ritual keagamaan masih tetap dilakukan oleh masyarakat Bali untuk menghilangkan pengaruh jahat dari kekuatan gaib pada manu- sia yang lahir pada hari tumpek wayang. Pertunjukan wayang seperti itu disebut dengan pertunjukan wayang sapuh leger, atau wayang pengruwatan bahkan saat ini sering dilakukan dengan upacara pengeruwatan masal. Dalang yang dianggap memiliki kemampuan untuk meruwat, mengahapuskan kekuatan jahat yang mempengaruhi manusia sering disebut dengan Mangku Dalang dan di Jawa disebut dengan Ki Dalang (Soedarsono, 1974 : 28).

Dari Penelitiannya G. J.A. Hazeu dalam disertasinya yang berjudul, Bijdrage Tot de Kennis van het Javaanische Tooneel, 1897, menyebutkan bahwa pertunjukan wayang adalah pertunjukan bayang-bayang (Mulyono, 1978 : 7). Pertunjukan bayang-bayang ini pada jaman pra Hindu merupakan pertunjukan ritual sebagai pemujaan terhadap roh nenek moyang. Pertunjukan bayang-bayang inilah, sekarang dikenal dengan pertunjukan wayang yang tidak hanya untuk menyebut pertunjukan wayang kulit tetapi juga pertunjukan wayang orang. Prasasti Tejakula (987), menyebutkan ada pertunjukan wayang dengan istilah "parbwayang", "aringgit" dan "patapukan". "Parbwayang" dan "aringgit" oleh R Goris diartikan pertunjukan wayang, "patapukan" diartikan pertunjukan topeng (Kartodirdjo, 1976 : 185).

Permasalahan yang muncul dalam penulisan ini adalah bagaimana implementasi pertunjukan wayang sebagai media komunikasi simbolik prilaku manusia dalam bidang budaya dan agama di Bali. Apakah tindakan manusia dalam menemptakan pertunjukan wayang sebagai warisan budaya dan kepercayaan animisme dan dinamisme pada masa pra Hindu masih mempengaruhi orang Bali dalam mempertahankan nilai budaya dan agama Hindu, merupakan permasalahan yang dikaji dalam tulisan ini.

Tindakan manusia didorong oleh rangsangan mental, hati atau pikiran manusia, persepsi, dan kemudian baru melakukan tindakan yang oleh Ritzer disebut dengan istilah dorongan konsumsi (Ritzer-Goodman,2004:274-276). Rangsangan mental yang mempengaruhi perasaan dan pikiran sehingga memunculkan sebuah persepsi, yang mendorong sebuah tindakan sangat dipengaruhi oleh nilai-nilai yang ditampilkan dalam pertunjukan wayang. Pertunjukan wayang menawarkan nilai dan makna serta akibat yang ditimbulkan dalam bentuk estetik, sehingga wayang sebagai media komunikasi perlu dimaknai, diinterpretasi dan dipahami sebagai pedoman dalam bertindak.

\section{METODE PENELITIAN}

Sebuah penulisan ilmiah sangat ditentukan oleh prosedur metodologi dalam dalam mengumpulkan 
dan menemukan data serta relevansi teori yang digunakan sebagai alat analisis. Prosedur pengumpulan data dalam penulisan ini dilakukan dengan menggunakan metode penelitian kualitatif. Peneliian kualitatif tidak sekedar mendiskripsikan data yang telah dikumpulkan melalui observasi, wawancara, dan studi perpustakaan tetapi berusaha mencari makna dibalik diskripsi itu (Ratna, 2010:94). Sebagai alat analisis penulisan ini menggunakan teori interaksi simbolik dan teori komunikasi.

Teori dalam hal ini dapat digunakan apabila dapat menunjukan adanya hubungan antara data yang tersusun secara sistematis dan memiliki makna yang dapat dipahami (Satori dan Komariah, 2009:5-6). Makna yang dipahami adalah wayang mengandung simbol prilaku manusia. Wayang juga dapat dipahami sebagai praktek budaya pengeruwatan dan pemujaan pada leluhur sebagai manifestasi Tuhan. Manusia lahir ke dunia merupakan pejelmaan leluhur dengan segala dosa dan perbuatannya dan dosanya itu akan dapat dibersihkan melalui pertunjukan wayang. Teori Interaksi simbolis memusatkan perhatian pada dampak dari makna dan simbol prilaku dan interakasi manusia. Mead, sebagai tokoh teori interaksi simbolis, membedakan prilaku manusia menjadi prilaku lahiriah dan prilaku tersembunyi. Prilaku tersembunyi adalah proses berpikir yang melibatkan simbol dan arti, sedangkan prilaku lahiriah adalah prilaku sebenarnya yang nampak dan dapat diamati. Prilaku tersembunyi itulah yang menjadi perhatian utama teori interaksi simbolik (Ritzer, Doglas, 2010: 293). Prilaku tersembunyi itu bagi orang Bali terdapat pada orang yang lahir pada wuku tumpek wayang, berdasarkan mitos merekan dikejar-kejar oleh Batara Kala untuk di bunuh.

\section{HASIL DAN PEMBAHASAN}

\section{Wayang Sebagai Media Komunikasi Simbolik.}

Wayang sebagai media komunikasi simbolik sudah dilakukan pada jaman pra Hindu, ketika kepercayaan pada alam, seperti batu besar, hutan dan pohon besar memiliki kekuatan gaib yang bisa mengganggu kehidupan manuisia. Komunikasi dalam hal ini adalah komunikasi dengan kekuatan yang ada diluar kemampuan manusia untuk melihat yaitu komunikasi supra natural. Kekuatan gaib yang ada dipohon kayu besar dan batu-batu besar adalah roh nenek moyang yang kalau tidak diadakan upacara secara rutin setiap tahun sekali akan mengganggu kehidupan manusia. Upacara pemujaan pada roh dilakukan dengan menggunakan sarana, boneka nenek moyang yang dibuat dari kulit kayu, sesajian, kemudian, lampu bambu (bobok) untuk menyinari boneka nenek moyang yang dipimpin oleh seorang Syaman atau kepala suku. Syaman atau kepala suku adalah orang sakti yang dianggap memiliki kemampuan untuk menguhungkan manusia dengan roh atau kekuatan alam yang ada diluar manusia, sehingga mereka sangat dihormati dan ditakuti. Sebagai pemimpin upacara, Syaman mengantarkan upacara tersebut dengan mengucapkan mantra-mantra, sehingga boneka nenek moyang yang di sorot dengan lampu, bayangannya bergerak-gerak seolah-olah menyampaikan sesuatu. Bergerak-geraknya bayangan boneka nenek moyang itu diyakini bahwa roh yang diundang telah datang untuk mengabulkan apa yang diinginkan dalam melaksanakan upacara itu ( Mulyono, 1978 : 43). Upacara pemuajaan pada roh dengan menggunakan pertunjukan wayang sebagai media adalah bentuk komunikasi antara manusia dengan roh melalui kemampuan gaib yang dimiliki oleh seorang dalang.

Upacara ini dilaksanakan ditempat yang khusus seperti di dalam hutan, di pinggir sungai dan di pinggir pantai, pada waktu yang khusus (Mulyono, 1978 : 43). Tempat khusus bagi orang Bali yang dianggap memiliki kekuatan gaib dan bisa mengganggu manusia adalah simpang empat yang besar (perempatan agung), simpang tiga (pahteluan), pinggir sungai, pantai dan gunng. Waktu khususn yang dianggap memiliki kekuatan gaib dan bisa mengganggu manusia adalah sore hari, pada saat pertemuan antara siang dengan malam (sandikala), tengah malam tepat pada jam dua belas (tengah lemeng), atu juga pagi har, pada saat pertemuan antara malam denganpagi harii (ngedaslemahang), serta jamn dua belas siang, yaitu pertemuan antara siang dengan sore (tengaitepet).

Dalam kaitannya dengan tradisi pertunjukan bayangbayang jaman pra Hindu, yang dimaksud dengan bayangan dalam hal ini adalah boneka wayang yang dibuat dari kulit dan dipantulkan melalui kelir dengan menggunakan lampu blencong yang dibawa sendiri oleh dalang (Clara, 1987:156). Dari uraian di atas maka kata wayang yang diartikan pertunjukan bayang-bayang hanya digunakan untuk menyebut pertunjukan wayang kulit, tanpa pernah mengaitkan kata wayang dengan pertunjukan lainnya seperti kata wayang dalam pertunjukan wayang wong. Kata bayang-bayang dalam hal ini selalu dikaitkan dengan bayangan boneka wayang yang ada di Balik kelir yang disorot dengan lampu blencong. Ketika kata wayang tidak hanya digunakan untuk menyebutkan pertunjukan wayang kulit, tetapi juga untuk menyebutkan pertunjukan wayang wong, maka bayang-bayang dalam hal ini tidak hanya diartikan bayangan dari boneka wayang yang dibuat dari kulit, tetapi memiliki arti lain yang lebih luas (Soedarsono, $1972: 63$ ).

Pertunjukan dramatari yang diambil dari karakter wayang dan gerak-gerak wayang kulit yang ditarikan 
oleh orang dengan cerita Ramayana juga disebut dengan pertunjukan wayang yaitu pertunjukan wayang wong. Dengan demikian maka kata wayang dalam wayang wong tidak lagi dapat diartikan sebagai bayang boneka wayang, tetapi bayangan karakter dan prilaku dari penokohan dalam lakon yang ditampilkan menjadi sebuah pertunjukan wayang wong (Mulyono, 1979). Kata wayang dalam hal ini adalah cerminan karakter dari tokoh-tokoh wayang yang direfleksikan melalui pertunjukan dramatari wayang wong. Komunikasi reflektif dari kakater tokoh-tokoh yang ini melalui pertunjukan wayang wong akan dapat diterjemahkan dan diinterpretasikan untuk dijadikan pedoman prilaku se-hari-hari dalam kehidupan masyarakat. Bayangan yang dimaksud dalam hal ini bukan bayang boneka wayang tetapi bayangan nilai moral dan nilai etika yang dapat membentuk karakter dan prilaku manusia dalam kehidupan bermasyarakat.

Wayang sebagai sebuah seni pertunjukan tidak hanya merupakan sebuah kreativitas seni tetapi merupakan kreativitas budaya yang di dalamnya mengandung : 1) system keteraturan makna dan symbol, 2) makna-makna yang ada dalam pertunjukan wayang ditranmisikan secara historis, 3) makna dan symbol yang ada dalam pertunjukan wayang dapat digunakan sebagai kontrol prilaku, 4) makna dan symbol harus dipahami, diterjemahkan dan diinterpretasikan (Jaeni, 2012 : 2). Pertunjukan wayang sebagai sebuah kreativitas seni dapat memberikan kenikmatan, keindahan, dan kesenangan bagi penonton, tetapi sebagai sebuah kreativitas budaya, pertunjukan wayang dapat dijadikan sumber gagasan, ideology da pedoman prilaku. Pertunjukan wayang telah menempa krangka mental kita, tekstur emosional kita, bahasa kita, pemahaman kita terhadap masa lalu dan masa sekarang dan perasaan-perasaan kita terhadap orang lain menyebabkan pertunjukan wayang dapat dikatan sebagai produsen ideology. Yang dimaksud ideology dalam hal ini adalah krangka mental, konsep, katagori, perbandingan pemikiran dan sistem representasi yang diterapkan oleh kelas sosial atau kelompok tertentu untuk memahami, mendefinisikan, mengerti dan mengubah cara-cara masyarakat berfungsi (Smiers, 2009 : 18). Krangka mental, konsep berpikir, katagori serta perbandingan cara berpikir dan sistem representasi dalam masyarakat semuanya bisa didapatkan dengan memahami, menginterpretasikan dan meterjemahkan makna dan symbol yang ditampilkan dalam pertunjukan wayang.

Seniman menciptakan bentuk seni budaya yang memungkinkan bagi masyarakat untuk berpartisipasi dan partisipasi masyarakat sebagai penikmat atau penonton telah menimbulkan adanya komunikasi. Seni pertunjukan sebagai sebuah media komunika- si menampilkan bentuk-bentuk ekpresif yang perlu diterjemahkan dan diinterpretasikan yang dapat digunakan sebagai kontrol prilaku. Dengan demikian perkembangan maupun perubahan kebudayaan sangat ditentukan oleh adanya kontrol prilaku yang ditawarkan oleh seni budaya. Sartono Kartodirdjo ( 1982 : 124-125) mengatakan bahwa semua seni budaya adalah medium dari transmisi, maka budaya dan kontinuitas budaya dalam perkembangannya dari jaman ke jaman sangat ditentukan oleh seni budaya. Pertunjukan wayang termasuk pertunjukan wayang wong adalah sebuah bentuk seni budaya yang sering digunakan untuk meneruskan adat kebiasaan, mendramatisasikan maknanya sehingga dapat mengajarkan kita bertindak (Kartodirdjo, 1982 : 124). Pertunjukan wayang termasuk pertunjukan wayang wong merupakan media komunikasi yang dapat mencerminkan tindakan teknis dalam kehidupan sosial budaya sehari-hari yang oleh Jaeni (2012 : 71), tindakan teknis itu disebut dengan tindakan reflektif. Manusia dalam melakukan tindakan tidak langsung bertindak tetapi mulai dari rangsangan mental manusia mulai dari berpikir dan pikiran ini bisa dibentuk oleh karakter-karakter tokoh yang dipertunjukan dalam wayang. Tahap berikutnya adalah dorongan persepsi, manusia mulai melakukan penilaian pantas atau tidak sesuatu itu dilakukan yang dapat didapatkan dari bagaimana pertunjukan wayang memberikan gambaran mengenai sebab dan akibat sebuah tindakan. Tahap ketiga adalah dorongan manipulasi yang artinya adalah manusia melakukan introspeksi diri untuk melakukan hal-hal yang telah dianggap pantas atau tidak. Dorongan selanjutnya adalah melakukan tindakan yang sudah dibayangkan sebab dan akibatnya.

Kaitan antara wayang dan prilaku manusia adalah pengaruh pertunjukan wayang terhadap sikap mental dan cara berpikir manusia di dalam berbicara bertindak. Tanpa disadari oleh manusia bahwa sikap mental dan cara berpikir manusia dalam berbicara dan bertindak dipengaruhi oleh pertunjukan wayang. Pertunjukan wayang dapat mempengaruhi prilaku manusia, karena pertunjukan wayang adalah media komunikasi yang paling efektif di dalam menanamkan nilainilai tertentu yang dapat mempengaruhi cara berpikir manusia. Pertunjukan wayang sebagai pedoman prilaku yang mengacu pada ajaran agama, tidak hanya digunakan oleh agama Hindu dalam menyebar luaskan nilai-nilai agama melalui cerita Mahabarata dan Ramayana, tetapi penyebaran agama Islam di Jawa juga menggunakan pertunjukan wayang.

Sebagai media komunikasi pertunjukan wayang telah digunakan oleh sunan Kalijaga untuk menyebarkan agama Islam di Jawa maupun penyebaran agama Islam di Lombok yang dilakukan oleh Sunan Prap- 
en dan Pengarena Mangkubumi. Sunan Prapen dan Pangeran Mangkubuni sebagai penganut aliriran Sufi yang mempercayai adanya hubungan komunikasi antara roh manusia dengan Tuhan mempertahankan wayang sebagai media komunikasi. Menurut Sunan Kalijaga, ketika manusia ingin menunju ke hadirat Iillahi ada lima jalan yang dapat ditempuh yaitu ; "Syariat" (sembah raga), "Tarikat" (sembah kalbu), "Hakekat" (sembah jiwa), "Ma'rifat" (sembah rasa), "Mahabbah" (cinta suci) (Mulyono, 1983:59). Kelima jalan ini akan dapat di sebar luaskan melalui pertunjukan wayang, karena pertunjukan wayang disamping sebagai tontonnan yang memberikan kenikmatan estetik atau hiburan, juga sebagai tuntunan yang dapat memberikan siraman rohani. Sebagai tuntunan pertunjukan wayang dapat menggerakan pikiran sehingga manusia mampu menggunakan logika. Pertunjukan wayang juga menggerakan rasa atau hati nurani sehingga manusia mampu membedakan mana yang benar dan mana yang salah. Pertunjukan wayang mampu menggerakan karsa, sehingga manusia memnajdi kreatif untuk menghasilkan sesuatu yang berguna bagi dirinya dan masyarakat (Bastomi, 1993 : 52).

\section{Wayang Dalam Praktek Budaya dan Agama.}

Memahami dan mengkaji pertunjukan wayang adalah memahami dan mengkaji nilai-nilai budaya dalam praktek kehidupan se hari-hari sebagai pedoman prilaku. Beranalogi dari pandangan Bastomi (1993 : 37), bahwa budaya Jawa secara esensial memiliki lima karakteristik yaitu : 1) Religius, Non doktriner, Tolerans, Akomudatif dan Optimistik, maka akan dapat diamat bahwa petrunjukan wayang mengintegrasikan kelima nilai tersebut. Nilai dalam konteks budaya yang dapat dipahami melalui pertunjukan wayang, mempunyai dua makna yaitu : 1) Nilai merujuk pada kwalitas produk budaya (Cultural Goods) yang artinya bahwa produk budaya yang dihasilkan layak dihargai atau perlu dicela, 2) Nilai merujuk pada prinsip moral yang tujuan dan standarnya dianut oleh masyarakat, artinya nilai adalah standar moral yang telah diakui oleh masyarakat (Tester, $2003: 5$ ). Pertunjukan wayang telah mengintegrasikan kedua makna nilai tersebut, karena pertunjukan wayang telah diakui sebagai budaya yang luhur, dan di dalamnya terdapat prinsip-prinsip moral yang telah diakui oleh masyarakat bias menawarkan mana yang baik dan mana yang buruk, mana yang harus diikuti dan mana yang harus dicela.

Dalam pertunjukan wayang ada nilai pembersihan, bahwa kotoran atau "mala" yang dibawa sejak lahir oleh manusia itu dapat di ruwat dengan pertunjukan wayang. Wayang pengeruwtan ini oleh orang Bali dilakukan ketika ada seorang anak yang lahir pada wuku wayang maka diadakan pertunjukan wayang yang intinya adalah membuat air suci (ngarge tirta) untuk di percikan pada anak yang diruwat. Pertunjukan wayang pengeruwatan ini dalam masyarakat Bali disebut dengan wayang Sapuh Leger. Disamping sebagai praktek budaya, nilai-nilai riligius dalam pertunjukan wayang dapat di pahami melalui lakon, misalnya kematian Bisma yang menunggu Matahari, berjalan ke utara, menunjukan bahwa perjalan suci itu ada ke utara, dalam masyarakat Bali dikenal dengan istilah "kaje" ke gunung, sehingga gunung dianggap sebagai lambing kesucian lambang tenpatnya para dewa.

Dalam masyarakat Bali pertunjukan wayang juga merupakan bagian dari upacara yadnya yang dikenal dengan Panca Yadnya yaitu : Dewa Yadnya, Pitra Yadnya, Rsi Yadnya, Buta Yadnya dan Manusa Yadnya. Pertunjukan wayang sebagai bagian dari upacara yadnya bersifat memberikan penekanan atau penjelasan terhadap upacara yadnya, sehingga lakon pertunjukan wayang akan disesuai dengan upacara yadnya yang dilakukan. Misalnya kalau upacara yang digelar adalah Dewa Yadnya maka ceritanya adalah Bima mencari tirta kamadalu, kalau upacara yang digelar adalah Pitra Yadnya maka cerita yang digunakan adalah Bima Swarga, Kalau upacara yang digelar adalah Manusa Yadnya, otonan atau 3 bulanan, maka cerita yang digelar lahirnya Gatot Kaca, Kalau upacara upacara yang digelar adalah Buta Yadnya cerita yang digelar adalah Bima Jadi Caru.

Cerita yang digunakan itu adalah merupakan keterkaitan antara sikap mental dan prilaku manusia di dunia sangat ditentukan oleh Tuhan. Oleh karena itu perbaikan sikap mental tidak hanya di tuntun secara sekala secara dunia nyata, tetapi harus dituntun secara niskala, dunia yang kasat mata yaitu Tuhan. Dengan demikian pertunjukan wayang akan menghubungkan antara kekuatan Tuhan dengan kekuatan di alam nyata, dan penghubungnya itu adalah Dalang. Dalam pertunjukan wayang dalanng dalang sering menunjukan bahwa Tuhan dapat berhubungan langsung dengan Manusia yang sudah memiliki kesucian yang tinggi. Arjua ketika mendapatkan senjata Geni Astra, dari dewa Indra, dalang menunjukan bahwa Dewa Indra dapat berbicara secara langsung kepada Arjuna serta memberikan senjata Geni Astra.

Pertunjukan wayang memmberikan pedoman untuk dapat menilai mana yang baik dan mana yang buruk, sehingga tidak memberikan doktrin bahwa pertunjukan wayang hanya menunjukan kebaikan dan kebenaran saja. Pertunjukan wayang memberikan kebebasan bagi penonotn, pengamat atau masyarakat secara umum untuk memahami nilai-nilai tersebut serta mengaplikasikannya dalam kehidupan se-harihari. Misalnya dalam cerita Kumbakarna Lina, ini 
menunjukan bahwa Kumbakarna sangat sadar bahwa kakaknya Rahwana adalah raja yang sombong, angkuh dan penuh dengan sikap angkara murka. Artinya tidak ada orang yang boleh lebih hebat dan lebih berkuasa daripada dirinya sendiri, tetapi Kumbakarna dalam pertempuran bukan membela kekuasaan kakanya sebagai raja yang angkara murka, tetapi membela kerajaan Alengka yang sedang diserang oleh pasukan kera dari Ramadewa. Dalam hal ini pertunjukan wayang tidak serta merta memberikan doktrin bahwa Rahwana adalah raja yang jahat, sombong, angkara murka dan angkuh, sehingga semua pengkikutnya atau pihaknya adalah kelompok yang jahat.

Nilai akomudatif, adalah sikap yang ditunjukan oleh Pandawa yang bersaudara lima dengan dua ibu saling menghargai dan saling menghormati di antara mereka. Dalam hal itu kebenaran tidak bisa diperjuangan hanya dengan darma, tetapi harus didukung oleh sikap-sikap ksatrya yang ditampilkan dengan kekuatan dan kecerdasan. Sikap ini diwakili Bima dan Arjuna. Sikap yang setia dan rela berkorban bagi Sahadewa dan Nakula mencerminkan kesadaran yang tinggi dalam mendukung kebijaksanan yang ditampilkan oleh Yudistria. Sikap akomudatif ini adalah sikap yang integrated dari berbagai unsur, sehingga menjadi semboyan bagi kita di Bali bahwa dalam menghadapi hidup supaya seperti "sampat" (sapu) artinya bersatu agar semua tantangan bisa diatasi. Dan, ini sering di jadikan semboyan bagi kita sebagai bangsa Indonesia "bercerai kita runtuh bersatu kita teguh". Panca Pandawa ini adalah lambang persatuan yang mengakomudasi berbagai karakter menjadi satu kekuatan untuk mempertahankan kebenaran.

Nilai optimistik, adalah semangat, keinginan untuk maju, kompetitif dan nilai perlawanan yang untuk membela dan mempertahankan kebenaran yang dituangkan dalam epos Mahabarata dan Ramayanan. Oleh karena itu Mahabarata dan Ramayana dijadikan sumber lakon utama dalam pertunjukan wayang. Nilai optimistik ini dibanguna oleh Sri Kresna dalam Perang Brata Yuda. Ketika Arjuna merasa bersalah, rendah diri dan pesimistis untuk menghadapi saudara-saudaranya, gurunya dan kakeknya yaitu Bisma, Sri Kresna selalu mengingatkan Arjuna bahwa mereka bukan sebagai saudara, bukan sebagai guru, dan bukan sebagai Kakek tetapi hadapi mereka sebagai kekuatan yang tidak mampu melepaskan diri dari kukungan kejahatan.

Harus dibedakan antara saudara, guru, dan kakek dengan kebaikan dan kebenaran, bahwa saudara tidak akan bisa dihapuskan, guru akan tetap guru, kakek tak akan tergantikan, tetapi perbuatan jahat harus dilawan dan dimusnahkan. Dorongan Kresna kepada
Arjuna merupakan nilai optimistis agar Arjuna tidak ragu-ragu lagi dalam memperjuangkan kebenaran.

\section{SIMPULAN}

Wayang sebagai sebuah tradisi seni budaya dalam bentuk pertunjukan, merupakan warisan dari jaman pra Hindu yang fungsinya adalah sebagai pemujaan pada nenek moyang agar tetap memberikan perlindungan pada manusia dan masyarakat. Kedatangan pengaruh India telah menyempurnakan pertunjukan wayang baik dari segi fungsi maupun estetikanya. Dari segi fungsi wayang tidak hanya digelar sebagai ritual tetapi sebagai media pendidikan untuk memahami budaya dan ajaran agama Hindu serta pembentukan prilaku budaya dan ajaran agama Hindu. Dari segi estetika pertunjukan wayang mulai memasukan unsure-unsur pendramaan yang berpedoman pada alur cerita yang bersumber pada Mahabarata dan Ramayana. Pergulatan antara karakter yang baik dalam pertunjukan wayang dapat dijadikan pedoman prilaku bagi masyarakat yang bercermin pada karakter tokoh yang dianggap baik dan benar serta mengintrospeksi prilaku yang mencerminkan keburukan dan kejahatan. Banyak nilai yang di tawarkan oleh pertunjukan wayang sebagai kwalitas budaya yang dalam kehidupan se-hari-hari pantas dihargai atau patut di cela sebagi sesuatu yang dianggap tidak bermoral.

Standar nilai yang ditawarkan oleh pertunjukan wayang sebagai cultural goods atau budaya yang berkwalitas, sesungguhnya telah diakui oleh masyarakat sehingga melalui pertunjukan wayang, masyarakat mampu memilah mana yang baik dan mana yang buruk dan mana yang pantas untuk dilakukan dan mana yang tidak pantas bahkan patut di cela. Memahami pertunjukan wayang secara utuh, baik dari segi cerita, karakter tokoh maupun pristiwa yang ditampilkan akan dapat dijadikan pedoman prilaku dalam pergaulan sosial di era global ketika orang mencari dan menelusuri identitas sebagai jati diri masyarakat Indonesia yang pluralistis.

\section{DAFTAR RUJUKAN}

Bastomi, Suwaji, 1993, Nilai-Nilai Seni Pewayangan. Semarang : Dahara Prize.

Giddens, Anthony, 2009, Kapitalisme Dan Teori Sosial Modern Suatu Analisis Karya Tulis Marx, Durkheim Dan Max Weber. Jakarta : Universitas Indonesia Press.

Groenendael, Victoria M. Clara Van, 1987, Dalang Di Balik Wayang. Jakarta : PT Pustaka Utama Grafiti. 
Jaeni, 2012, Komunikasi Estetik Menggagas Kajian Seni dari Peristiwa Komunikasi Pertunjukan. Bogor : Institut Pertanian Bogor Press.

Kartodirdjo, Sartono, 1976, Sejarah Nasional Indonesia Jilid II. Jakarta : Departemen Pendidikan Dan Kebudayaan.

Kartodirdjo, Sartono, 1982, Pemikiran Dan Perkembangan Historiografi Indonesia Suatu Alternatif. Jakarta : Gramedia.

Keith, Tester, 2003, Media, Budaya Dan Moralitas. Yogyakarta : Kreasi Wacana.

Mulyono, Sri, 1983, Simbolisme Dan Mistikisme Dalam Wayang Sebuah Tinjauan Filosofis. Jakarta : Gunung Agung.

Muyono, Sri, 1978, Wayang Asal Usul, Filsafat Dan Masa Depannya. Jakarta : Gunung Agung.

Ritzer, George - Douglas J. Goodman, 2010, Teori Sosiologi Modern. Jakarta : Kencana Prenada Media Group.

Smiers, Joost, 2009, Arts Under Pressure Memperjuangkan Keaneka Ragaman Budaya di Era Globalisasi. Yogyakarta : Insist Press.

Soedarsono, 1972, Djawa Dan Bali Dua Pusat Perkembangan Dramatari Tradisional Di Indonesia. Yogyakarta : Gadjah Mada University Press.

Soedarsono, 1974, Beberapa Catatan Tentang Seni Pertunjukan Indonesia. Yogyakarta : Konservatori Tari Indonesia. 